Rubey, University of California, Los Angeles; the Arthur L. Day Medal, to Keith E. Bullen, University of Sydney. Associated societies took part in the celebrations, namely, the Mineralogical Society of America, the Paleontological
Society, the Society of Economic Geologists, the Geochemical Society and the National Association of Geology Teachers. Some of these societies also presented awards at the meeting.

\title{
PREPARATION AND PUBLICATION OF GEOLOGICAL JOURNALS
}

\begin{abstract}
A TWO-DAY meeting of editors of British geological journals, sponsored by Messrs. Oliver and Boyd, Ltd., was held in Edinburgh during October 11-12. The meeting covered a wide range of topics including instructions to authors; refereeing; preparation of manuseript for printer; relations with printer; design and layout of British geological journals; blockmaking; sales, distribution and costs; index cards.

Suggestions as to ways of reducing editorial chores were few. The solution seems to rest largely with the author and the better preparation of his seript. The World List reference style has been adopted by most geological journals in the past fow years, but inconsistency in references still remains an editorial problem. More uniformity in instructions to authors was welcomed by some, but not all, of the editors present. It was understood that the Geological Society of London's detailed notes to authors are due to be revised, and the hope was expressed that much of the material in the new edition would prove to be of general use. Certainly the plea for a more uniform treatment and a higher standard of diagrams was welcomed by those present.
\end{abstract}

Mr. Thomson (Oliver and Boyd) discussed editorial relationships with the printer. A clean copy, as always, is much to be preferred. Once the printer knows a journal style, only a small amount of mark-up, such as the centring of headings and indenting, is required. $\mathrm{He}$ revealed that printers generally keep notes of the style of each journal, including the spelling of scientific words peculiar to that journal, and that uniformity of style from issue to issue is achieved by using the same compositor.

It was agreed that authors did not appreciate the high costs involved in even minor alterations (as was proved by a visit to the compositors' room), and all the editors welcomed the opportunity of acquiring copies of Authors' Alterations Cost Money and Delay, produced by the British Federation of Master Printers. This pamphlet would be sent out to authors at the proof stage. The suggestion was made that authors should be charged for all alterations, printer's errors apart, that they made to the proofs. The advantages of this scheme lie in the saving in costs and in quicker publication sine $\theta$ it might be possible to omit the galley proofs and go straight into page proof. The disadvantage lies in a less-than-perfect final copy in which the errata are confined to a short appendix.

Mr. Iran Wilson, chairman of the Scottish Council of Industrial Design, provided one of the highlights of the meeting by making a candid assessment of the design and layout of British geological journals. He classified them into three groups, 'Pleasing', 'Nothing special but some care shown', and thirdly, 'Nothing done since first published'. It would be invidious to classify them here, but several general criticisms are worth making. They included: poor type-faces; wrong size of type in relation to the length of line; too yellow a paper; paper too bulky; paper of different colours in the same issue; too many type faces (and therefore added costs); generally poor quality of diagrams; and, with one exception, unnecessarily drab colours of the covers. He wondered why journals did not print more frequently on both sides of the art paper used for plates. He suggested that some schools of art or of printing would welcome the opportunity to re-design a journal. The defence to Mr. Wilson's arguments was that more attractive layouts usually cost more money, and if costs increased by, say, 10 per cent, then 10 per cent fewer papers would be published, to which Mr. Wilson rejoined that there is little use in printing papers if they are not readable. The general feeling among the editors was that presentation could certainly be improved and that this could be done in collaboration with the printer. A useful suggestion made during this discussion was that the page numbers should be printed on the spine of each part.

Mr. Hislop (Hislop and Day) discussed methods of blockmaking. He thought that geological diagrams were better than the average, his main criticism being that originals are generally too large. Reduction to less than half size should be avoided. He reminded editors and authors of the necessity of marking the top of each photograph, and of having soft rather than contrast prints. Contrast can always be increased but not reduced. He thought that Letraset was good for lettering and recommended a new photographic process of lettering called Starlettograph-Lichtsatz (Munich).

Mr. Douglas Grant (Oliver and Boyd) reminded editors of the necessity of watching costs. They should ask for detailed invoices from their printers so that the costs of the different items such as paper, composition, corrections, machining, etc., can be determined. Offprints should be ordered before printing so that the required number of plates, and in long articles certain of the printed sheets, can be run off during the main printing. Variations in type sizes and type faces can increase printing costs and should be reduced to a minimum: a supply of reviews and short articles should be kept so that the part can be brought up to a multiple of 16 pages: wherever possible vertical rules in tables should be removed because of the expense of setting.

The meeting was told by Mr. Inglis (Oliver and Boyd) of discounts, commission and distribution. Individual small costs add up to impressive totals, ranging from invoices at $\frac{1}{4} d$. each, through envelopes costing $1 \frac{1}{4} d$. to $6 d$. for the carton sizes, to postages for larger parts at $2 s .3 d$. Small wonder that some journals (not geological as yet) find it difficult to run to six parts annually and are considering a quarterly issue.

Index cards, the last item on the agenda, had been tried out by the editors of the Transactions of the Edinburgh Geological Society in a recent issue, with the view of providing subscribers with abstracts for use in filing systems. Each copy contained 5 in. $\times 3$ in. cards, one for each of the papers, bearing the author's name, title of the paper, journal reference and the author's abstract (not exceeding 250 words). The cost worked out at a little less than $1 d$. a card and represented some 3 per cent of the total cost of the part. Such cards were welcomed, but it was felt that their spread to other journals would be more influenced by subscriber pressure than by editorial decision.

The overall impression at the end of the two days of useful discussion was that it was greatly to the advantage of journals that the editors should see more of the printer and that a more satisfactory relationship should be established between author, editor and printer.

G. Y. Craig 